\title{
Efficacy of Pneumatic Lithoclast in the Management of Urolithiasis in Upper, Middle and Lower Ureter
}

\author{
Iftikhar Ijaz*, Ijaz Ahmed Kharal, Rahat Usman and Junaid Habib Khan \\ Department of pediatrics, AIMC Jinnah Hospital, Pakistan
}

Received: February 15, 2018; Published: March 01, 2018

*Corresponding author: Iftikhar Ijaz, Department of Pediatrics, AIMC/Jinnah Hospital, Lahore. 47-B, DHA Phase 8 (Ex Park View), New Airport Road, Pakistan, Tel: 302 8420335; Email: driftikharijaz777@gmail.com

\begin{abstract}
BackGround: Pneumatic lithotripter breaks the calculi by oscillatory movement of a solid probe. It is very effective and least morbid approach for all kind of stones in middle and lower Ureter. Although devise is suitable for all parts of Ureter but in upper ureteric calculi, though small, there is a risk of push back in kidneys.
\end{abstract}

Objective: To determine the safety and efficacy of pneumatic lithoclast for calculi in different parts of the Ureter.

Methods: This was a comparative interventional longitudinal study conducted at depth of Urology K.E.M.U/Mayo hospital, Lahore over a period of 02 years from Jan 2015 till Jan 2017. Those 140 patients who met the inclusion criteria were enrolled for study. Diagnosis of ureteric calculi was confirmed by X- Ray KUB (kidney, Ureter, bladder) Ultrasound KUB and Intravenous Urography. Patients were explained all objectives, merits and demerits of the study and written consent were taken. Based on the location of ureteric stones, patints were divided in 03 groups, which were Group A (upper ureteric stones), B (middle ureteric stones) and C (Lower ureteric stones).

Results: Mean stone size for all 03 groups was comparable $(1.09+0.24 \mathrm{~cm}, 1.20+0.16$ and $1.2+0.20$ respectively. Upper ureteric stones (Group A) attained complete fragmentation in 44 patints, while extracorporeal shock wave lithotripsy was used for rest of 16 patients. Out of those 44 patients 31 had clearance on day 1, 4 at 2nd week and 9 at 6 weeks. All 37 patients in group B had stone clearance, 17 on day 1 and remaining 20 at 2 nd week, similarly all 43 in group $C$ had complete clearance, 26 at day 1 and 17 at 2 nd week. No complication in pre-op periods were recorded while 40 patients suffered complication in post-op period (Group A=11, group B=13, group $\mathrm{C}=16$ ).

Conclusion: Pneumatic Lithoclast is safe and effective procedure for ureteric stones. Overall success rate is $88.57 \%$ which is comparable to other reported studies. Adaptability of technique is helpful to achieve complete fragmentation and stone Free State.

Keywords: Pneumatic Lithoclast; Ureteric calculi; Ureter

\section{Introduction}

Litrature review reveals prevalence of urinary stones for ages as proved by different archeological studies. Renal and blaader stones were also discovered in Egypsian Mummies. Urolithiasis was associated with worst morbidity and mortality, although Egypsians were expert in conservative treatment but did not have enough expertise to take out urinary calculi $[1,2]$. Stone disease is on rise worldwide primarily as a result of increase in prosperity and changing dietary habits in almost all social groups of the world. Afro-Asian belt includes the United Arab Emirates, Sudan, Indonesia, Philippine, Saudi Arabia, Islamic Republic of Iran, Egypt, India, Myanmar, Thailand and Pakistan. The reported incidence of stone disease in these regions has been found to be $4-20 \%$ for all age groups $[3,4,5]$. In Pakistan prevalence of kidney stones is $16 \%$ as quoted by Rizvi et al. Incidence $(100,000)$ as extrapolated by operating room statistics varies in different geographical locations. It varies from 0.2-9.4 in the North, 10.5 in North Sindh, 200 in South Sindh and 11.1 to 28 in Balochistan [6] Pathophysiology of stone formation is an inter-play between promoters and inhibitors of crystallization, along with urine $\mathrm{PH}$ and urine flow rate.

Important promoters are crystals of calcium, oxalate, phosphate, magnesium ammonium phosphate, uric acid and cystine, while important inhibitors are citrate, magnesium, pyrophosphate, glycosaminoglycans, nephrocalcin and anatomical defects of urinary tract $[7,8]$ Patients with urolithiasis may present with colic in case of obstructing stone, pain arises in flank. Upper ureteric pain radiates to groin and testicles in men and labia majora in women, while middle ureteric stone pain mimicks appendicitis and diverticulitis on right and left side respectively. Lower ureteric 
stone symptoms mimick lower urinary tract infection symtoms, pain may radiates to tip of penis in male, other symptoms may be hematurea or infection related manifestations, in certain percentage stones are picked as incidental finding. Decision to treat kidney/ ureteric stone depends upon stone composition, size location and expertise of the surgeon. Not only various surgical techniques have evolved over the years but various lithotriptic techniques are in use for decades which includes shock wave lithotripsy, laser lithotripsy, and electro hydraulic and pneumatic lithotripsy. These techniques may be used through intra corporeal or extracorporeal method $[9,10]$. Comparing these methods in terms of safety, efficacy and cost effectiveness Pneumatic lithotripsy has been found to be most suitable choice.

Objective: To determine the efficacy and safety of pneumatic Lithoclast in the management of ureteric calculi in upper, middle and lower part of the Ureter.

\section{Patients and Methods}

This was comparative interventional longitudinal study, conducted at Department of Urology, Mayo Hospital Lahore over a period of 02 years from Jan 2015 till Jan 2017. 140 patients with ureteric calculi were taken on the basis of $95 \%$ confidence level, $10 \%$ prevalence of urolithiasis and $5 \%$ margin of error. Inclusion criteria were ureteric calculi, diagnosed on the basis of pain, lower

\section{Results}

Table 1: Size of stone $(\mathrm{CM})$ in treatment group. urinary tract symptoms and symptoms suggestive of obstructive uropathy. Diagnosis was confirmed by X-ray KUB (kidney Ureter bladder), intra venous Urography and ultrasonography. Patints having age $<12$ years, Skeleton deformity, non functioning kidneys, patients with ureteric pathology and ureteroscopic failure were excluded from the study. Out of total 156 patients 16 were excluded and 140 were finally enrolled. These 140 patients were divided into 3 groups depending on the location of ureteric stone. Group included patients with stone in upper Ureter, while Group B and C in middle and lower third of Ureter.

Selected patints underwent ureteroscopic Pneumatic lithotripsy under spinal or general anesthesia with the help of Wolf 8.5 for rigid Ureteroscopic and Wolf $2 \mathrm{~mm}$ pneumatic Lithoclast probe. At the end 4 frureteric stent was placed for 24 hours. Post operatively pain was managed with pain killers, Stone clearance was assessed by KUB on next day, cases where stone clearance was not complete, was assessed again at 6 weeks. Retained fragments at 6 weeks were labeled as failure of procedure and other modalities were used for fragments removal. Complications like fever, hematurea and stone migration was noted. Data was analyzed through SPSS 22.0. All qualitative data was presented as frequency and percentages and quantitative variable as mean + SD .ANOVA was applied for quantitative and Chi-square for qualitative variable. A p-value of $<0.05$ was taken as significant.

\begin{tabular}{|c|c|c|c|c|}
\hline & Group- A & Group- B & Group -C & Total \\
\hline No & 60 & 37 & 1.21 & 1.16 \\
\hline Mean & 1.09 & 1.20 & 0.20 & 0.22 \\
\hline SD & 0.24 & 0.16 & 1 & 0.9 \\
\hline Minimum (in cm) & 0.70 & 1 & 1.50 & 1.50 \\
\hline Maximum (in cm) & 1.50 & 1.50 & & \\
\hline
\end{tabular}

Mean age of 140 patients was $37.27+9.95$ years, minimum and maximum age of patients was 18 and 55 respectively. Overall gender distribution shows that there was female preponderance, 65 were males and 75 were female patients. 60 patients were assigned to group A, 37 to group B and 43 to group C (Table 1). Regarding stone location, in group A 41 patients had stone in right Ureter and 19 had stone in the left Ureter. In group B 28 patients had stone in the Table 2: Efficacy of stone clearance. right Ureter and 9 patients had stone in the left Ureter. In group C 25 and 18 patients had stones in the right and left Ureter respectively. Over all right sided stones were in 94 and left sided in 46 patients. Complete fragmentation of stones was observed in 44/60 patients in group A while all 37 and 43 in group B and C achieved complete fragmentation (Tables 2-4).

\begin{tabular}{|c|c|c|c|c|c|}
\hline & Group-A & Group-B & Group-C & Total & Cumulative \\
\hline 1 st day & 31 & 17 & 26 & $74(52.86 \%)$ & $74(52.86 \%)$ \\
\hline 2 weeks & 4 & 20 & 17 & $41(29.29 \%)$ & $115(82.14 \%)$ \\
\hline 6 weeks & $9+16(\mathrm{ESWL})$ & 0 & 0 & $25917.85 \%)$ & $140(100 \%)$ \\
\hline Total & 60 & 37 & 43 & 140 & 140 \\
\hline
\end{tabular}


Table 3: Pre and post operative complications in groups.

\begin{tabular}{|c|c|c|c|c|c|c|c|c|}
\hline \multirow{2}{*}{} & \multicolumn{9}{|c|}{ Complications } \\
\cline { 2 - 10 } & \multicolumn{2}{|c|}{ Group-A } & \multicolumn{2}{c|}{ Group-B } & \multicolumn{2}{c|}{ Group-C } & \multicolumn{2}{c|}{ Overall } \\
\cline { 2 - 9 } & Pre-Op & Post-0p & Pre-Op & Post-Op & Pre-Op & Post-Op & Pre-Op & Post-Op \\
\hline Yes & 0 & 11 & 0 & 13 & 0 & 16 & $0(0 \%)$ & $40(28.57 \%)$ \\
\hline No & 60 & 49 & 37 & 24 & 43 & 27 & $140(100 \%)$ & $100(71.43 \%)$ \\
\hline
\end{tabular}

Table 4:

\begin{tabular}{|l|c|c|c|c|c|}
\hline \multicolumn{2}{|c|}{} & Group-A & Group-B & Group-C & Total \\
\hline Complications & Fever & $1(9.09 \%)$ & $2(15.38 \%)$ & $3(18.75 \%)$ & 6 \\
\hline & Hematuria & $2(18.18 \%)$ & $11(84.62 \%)$ & $13(81.25 \%)$ & 26 \\
\hline & Stone Migration & $8(72.73 \%)$ & $0(0 \%)$ & $0(0 \%)$ & 8 \\
\hline \multicolumn{2}{|c|}{ Total } & 11 & 13 & 16 & 40 \\
\hline
\end{tabular}

\section{Discussion}

Urologic management has changed considerably over last 20 years. Various techniques of ureteroscopic and lithotripsy have been used Pneumatic lithotripsy has been most widely used method of stone disintegration [11]. Whatever the mode of lithotripsy used for ureteric stones, there is always a risk of stone migration upward. Pneumatic lithotripsy is more popular amongst urologist because of its low cost, high success rate, low complication rates and well established efficacy for different types of stones including calcium, oxalate monohydrate and cystine stones [12]. Overall success rate quoted for Pneumatic lithotripsy ranges from 70.7-96.8\% [13]. In this study overall success rate was $88.57 \%$, success rate for upper ureteric stones was $77.33 \%$, while it was $100 \%$ for middle and lower Ureter. Murtadhsa in his study reported success rate of $71.66 \%$, age range in his study was 17-52 years with male predominance (M: F ratio $1.4: 1$ ) [14].

Comparing success rates with other local studies reveal success rate of $92 \%$ by Shahid et al which is higher than our study and $87.9 \%$ by Hussain et al from Ziaudin hospital Karachi [15]. Study by Mareno et al reported overall success rate of stone clearance by $90 \%$, location wise it was $91.3 \%$ for upper Ureter and $88.9 \%$ for middle and lower Ureter [16]. Another local study by Akhtar et al reported complete fragmentation of $71.1 \%$ for upper ureteric stone, $97 \%$ for middle and $99.1 \%$ for lower ureteric stones [17]. Success rate for upper ureteric stone in our study is lower than study by Mareno et al but higher than study by Akhtar et al, while clearance of middle and lower ureteric stone in our study is higher than other studies. Complication rate in our study was $28.57 \%$ comparable to other studies. For upper ureteric stones complication rate was $18.33 \%$ while for middle and lower ureteric stone it was $35.13 \%$ and $37.20 \%$ respectively. Most studies published between 1996 and 2003 narrate an overall ureteroscopic complication as low as $7 \%$. Incidence of minor complication in our study was $4.5 \%$ as compared to $0-35 \%$ in other studies. Prophylactic antiobiotics were used routinely in all cases to cover pre and post operative complications [18-21].

\section{Conclusion}

Pneumatic lithotripsy is found to be safe and effective procedure with overall success rate of $88.57 \%$ which is in line reported by other studies. The only appreciable disadvantages of Pneumatic lithotripsy were the limitations of pro rigidity leading to hematurea and potential proximal stone migration during treatment.

\section{References}

1. Eknoyan G (2004) History of urolithiasis. Clinical reviews in bone and mineral metabolism. 2(3): 177-185.

2. Shah J, Whitfield H (2002) Urolithiasis through the ages. BJU Int 89(8): 801-810.

3. Van Dervoort K, Wiesen J, Frank R, Vento S, Crosby V, et al. (2007) Urolithiasis in pediatric patients: A single cente study of incidence, clinical presentation and outcome. The J Urol 177(6): 2300-2305.

4. Yasui T, guchi M, Suzuki S, Kohri K (2008) Prevalance and epidemiological characteristics of urolithiasis in Japan: National trends between 1965 and 2005. Urologgy 71(2): 2009-2013.

5. Sternberg K, Greenfield SP, Williot P, WanJ (2005) Pediatric Stone disease: an evolving experience. J Urol 174(4): 1711-1714.

6. Hussain M, Rizvi AH, Askari H, Sultan G, Lal M, et al. (2009) Management of stone disease: 17 years experience of stone clinic in a developing country. J Pak Med assoc 59(12): 843-846.

7. Srinivas S, Venkanna B, Madan Mohan E, Karishna Mc (2012) Urolithiasis overview. IJPRBA 1(1): 2031.

8. Curhan GC (2007) Epidimiology of stone disease. Urol Clin North Am 34(3): 287-293.

9. El-Hefnawy AS, Shokeir AA (2012) Diagnosis of urinary tract stones: An overview. Urolithiasis: Basic science and clinical practice. Springer pp. 243-250.

10. Reuter H, Kern E (1973) Electronic lithotripsy of ureteric calculi. J Urol 11092: 181-183. 
11. Sozen S, Kupeli B, Tune L, Senocak C, Alkibay T, et al. (2003) Management of ureteral stones with pneumatic lithotripsy: report of 500 patients. J Endourol 17(9): 721-724.

12. Lam JS, Greene TD, Gupta M (2002) Treatment of proximal ureteral calculi: holmium: YAG laser ureterolithotripsy versus extracorporeal shock wave lithotripsy. J Urol 167(5): 1972-1976.

13. Jeon SS, Hyun JH, Lee KS (2005) A comparison of holmium: YAG laser with Lithoclast lithotripsy in ureteral calcui fragmentation. Int J Urol 12(6): 544-547.

14. Murtadha MS, Majeed Aya-Tmam (2008) Evaluation of Pneumatic Lithoclast Efficacy in Treatment of Ureteric Stones. MJBU 26(1): 15-18.

15. Shahid MR, Muhammad RZ, Muhammed RB (2003) Pneumatic lithotripsy for the treatment of ureteric Calculi. Pak Armed Forces Med Journal 53(1): 44-46.

16. Arnada JM, Martinez GM, Salas JFL, Marroquin RAL (2004) Outpatient ureteroscop in ureteral calculi: Comparison of 4 different lithotripstors.
Boletin del Colegio Maxicano de Urologia. Academic Journal 12(1): 3235.

17. Akhtar MS, Akhtar FK (2003) Utility of the lithoclast in the treatment of upper, middle and lower ureteric calculi. Surgeon 1(3): 144-148.

18. Yao B, Ravery V, Delmas V, Boccon-Gibod L (2000) Does ureteroscopy still plays a role in the treatment of ureteral calculi? Progress en urologic. Journal de l'Association francaise d'urologie et de la Societe francaise d'urologie 10(4): 537-541.

19. Harmon WJ, Sershon PD, Blute ML, Patterson DE, Segura JW (1997) Ureteroscopy: current practice and long-term complications. J Urol 157(1): 28-32.

20. Fasihuddin Q, Hasan A (2002) Ureteroscopy (URS): an effective interventional and diagnostic modality. JPMA 52(11): 510-512.

21. Gettman MT, Segura JW (2005) Management of ureteric stones: issue and controversies. BJU Int 95(s2): 85-93.
(C) This work is licensed under Creative

Submission Link: http://biomedres.us/submit-manuscript.php

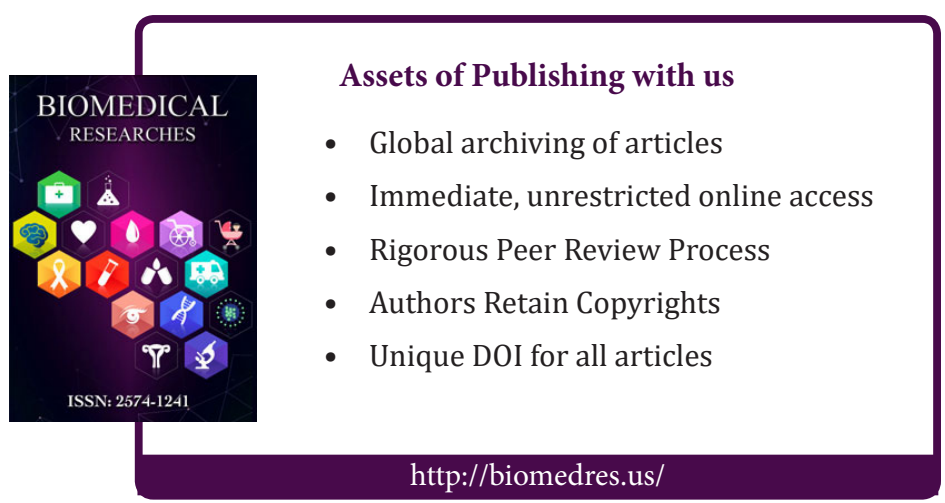

